\title{
Student Acceptance Of Clickers In Large Introductory Business Classes
}

\author{
Michael W. Preis, University of Illinois at Urbana-Champaign, USA \\ Gregory M. Kellar, Wright State University, USA \\ Elizabeth Crosby, University of Illinois at Urbana-Champaign, USA
}

\begin{abstract}
Today's NetGen students require more multimedia and interactive learning environments and greater participation than previous generations. Personal response devices (PRDs, sometimes called Audience Response Devices or ARDs, better known as clickers) show promise in helping to meet that need. This article explores the literature of PRDs to develop propositions about the impact of PRDs on learning in large introductory business classes (e.g., Principles of Marketing, Introduction to Supply Chain Management, Organizational Behavior, etc.). We report on two exploratory studies utilizing PRDs and discuss recommendations and observations on the use of PRDs.
\end{abstract}

Keywords: clickers; personal response devices (PRDs); audience response devices (ARDs); large classes

\section{BACKGROUND}

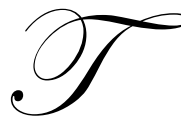

oday's students require more and more involvement in the teaching/learning process (Murphy and Smark 2006). A technology that could help teachers of introductory business classes to engage students directly in the learning process would be helpful. Personal Response Devices (PRDs/ARDs/clickers) show potential as just such a technology. This paper reports the results of a study that investigated the use of PRDs in large sections of introductory marketing classes. The article is written to help educators examine the benefits of using PRDs in large introductory business classes and to provide some guidance to instructors implementing such systems. We begin with a review of literature related to current challenges in teaching large classes and the use of PRDs in potentially meeting these challenges. This is followed by a case study of the use of PRDs and presentation of its findings. Implications from the case study of using PRDs in large sections are addressed and recommendations are made. We conclude with a discussion of limitations of this study and implications for future research.

\section{LITERATURE REVIEW}

The behaviors and attitudes of today's students have changed over the past decade (Murphy and Smark 2006; Skiba and Barton 2006), creating unique new challenges for business instructors. Today's students are more interested in music, fashion, sleeping, exercise, and social opportunities than in their classes (Ferrell and Gonzalez 2004; Tomkovick 2004). In particular, performing homework and attending classes are at the bottom of the list of desirable activities for students (Smart, Kelley, and Conant 1999). A second issue challenging instructors is that today's university students are more technologically savvy, more used to multi-tasking, need more interactivity and seem to have a need for constant stimulation and e-communication (Wallis et al. 2006; Skiba and Barton 2006). One study found that from $25 \%$ to $33 \%$ of students report they simultaneously IM, listen to music, use the computer, or even read, while watching TV (Wallis et al. 2006). This makes students today less tolerant of passive learning environments than in the past, i.e., they require more interactivity (Murphy and Smark 2006). "They are used to interactive, participatory, investigative enquiry. They have a very limited tolerance for knowledge transmission systems which require them to be passive observers (such as traditional lectures at university)" (Murphy and Smark 2006, p. 186). Further, Drea, Tripp and Stuenkel (2005) find that students perceive the use of interactive teaching methods such as simulations and games as positive uses of class time. In the words of one faculty member, "students 
today require more multimedia and technology-based tools to remain interested and motivated" (Smart, Kelley and Conant 1999, p. 210).

These two issues (declining student interest in classes and increasing expectations of interactive learning environments) are among the important issues driving a paradigm shift in higher education. Universities are increasingly expected to produce learning rather than simply provide instruction (Barr and Tagg 1995; Skiba and Barton 2006). Active learning, which encourages engagement with the material (Coker and White 1993), is becoming recognized as one of the principles of good undergraduate education (Chickering and Gamson 1987), This is expressed by the Cognitive-Interactionist Theory of Learning which states that students should be viewed as active participants in the teaching-learning process and that learning is an interactive process in which students are responsible participants (Coker and White 1993). Studies show that students who interactively participate in classes learn the material better, retain concepts longer, and can apply them more effectively than students who do not interactively participate in classes (Handelsman et al. 2004). Instructors are increasingly challenged to engage business students in meaningful learning activity during classes (Tomkovick 2004).

However, attempts to create interactive learning environments in university courses are complicated by the increasing need to teach large class sections (defined as larger than 100 students). Active learning is enhanced in smaller, rather than larger, sections, and large class sections place special demands on both students and faculty (Carbone 1998). Goldfinch (1996) found that students in small classes perform better on exams than students in large lecture sections. This effect on exam scores holds even if students from large classes have small recitation sections. The question of how to personalize large classes so that students feel engaged and so that more interactive learning occurs has been asked by many educators. Frequently, techniques that work in small classes are not scalable and will not work in large sections (Carbone 1998). However, small classes, or even small recitation sections, are not feasible in many universities. Unfortunately, large sections are likely to become more common rather than less common (Smart, Kelley and Conant 1999) due to increasing financial pressures on universities (Carbone 1998).

In this era of increasing numbers of large class sections for introductory courses, "faculty are making increased use of emerging technologies" as they work to create an atmosphere of interactive learning, (Smart, Kelley and Conant 1999, p. 210). However, not all instructors find a formula that works for them. A variety of techniques has been used by faculty as they attempt to engage students in large sections in course material (Carbone 1998). Although one study observed that technology is not widely used for pedagogical purposes in the classroom (Granitz and Hugstad 2004), other studies have found that the Internet and e-mail are often used for administrative purposes such as communicating with students and providing information (Davis 2002; Stern and Tseng 2002). Peterson (2002) found that a majority of marketing faculty use some form of technology in the teaching process, with presentation software (e.g., PowerPoint) being the most common. Several other forms of technology have also been used, including providing various online forms of information such as instructor home pages, lecture outlines, syllabi, student rosters, online homework, Internet and Web page projects (Clarke, Flaherty, and Mottner 2001), and course management software (CMS) such as WebCT and Blackboard. However, none of these technologies directly enhances interaction in the classroom setting. Further, while many technologies hold promise of affecting teaching and learning, claims of improvement are frequently buttressed only by anecdotal evidence (Young 2001). A technology that would improve students' active learning and participation in large class settings, that was relatively simple to incorporate into lectures, and that was shown to be effective through scientific study, would be helpful as a means of increasing student learning. Personal response devices, which have begun to be used in business classrooms are one technology that appears to fill all these requirements (Skiba and Barton 2006).

\section{HOW PRDS WORK}

Personal response device systems permit instructors to ask questions in their classes, receive real-time responses from the students, and provide immediate feedback to students. Through the use of presentation software, questions with multiple discrete options (such as true/false, yes/no, Likert-type, or multiple choice questions) are shown on a screen. Each student responds by pressing on his or her PRD the button that corresponds to his or her selected answer. The system captures each student's response individually and, when the instructor advances the slide, aggregate results can be presented graphically. When PRDs are registered to individual users, grading data can be captured for each student, thus giving feedback both on an individual level and classroom level. PRDs represent 
a potentially useful technology to enhance active learning, particularly if studies can show them to be both engaging and useful.

Several competing brands of Personal Response Systems (PRS) exist. They utilize three distinct components: individual PRDs used by students, a receiver to collect responses from student PRDs and connected to the instructor's computer, and software installed on the instructor's computer. When students respond to interactive questions posed by the instructor, each PRD transmits the response to the instructor's computer, where the software tallies and reports the class answers. Many PRD-systems fit seamlessly into PowerPoint. The creation of interactive slides can be learned in just a few minutes and can be used as parts of PowerPoint presentations or as stand-alone quizzes or query portions of a class. When used as parts of PowerPoint presentations, instructors advance presentations one slide at a time, as usual. When interactive slides are reached, "polling" (the capture of signals from individual students' PRDs) is opened. A real-time response counter may show the cumulative number of students that have responded at any instant. Polling can be closed manually when the number of students responding has ceased increasing or after a pre-set time (using a pre-set timer that can be varied for each interactive slide). When polling is closed the instructor can display the question and a histogram of the aggregated polling results.

Early PRD systems were hard-wired (Burnstein and Lederman 2006). Subsequent systems relied on infra red (IR) technology (the same as is used in many TV remote controls); these were limited to line-of-sight, had problems with signal interference, and could handle only a limited number of PRDs (typically around 30) (Horowitz 2006). Current technology uses radio frequency (RF) transmissions to overcome the limitations of IR systems. They do not require line-of-sight and can handle up to approximately 1,000 individual PRDs simultaneously. The technology is constantly improving. Earlier PRDs may have had an LED to indicate that a response had been received by the instructor's computer; newer designs incorporating LCD screens with the capability of displaying what response was recorded by the instructor's computer are under development. Also, software for installation on students' laptop computers, PDAs, or smart-phones, that provides the functionality of PRDs (virtual PRDs), is available or under development on some systems.

\section{USE OF PRDS IN OTHER DISCIPLINES}

While the business education literature has infrequently addressed the use of PRDs, other disciplines, such as biology, anatomy, and physics, have embraced the use of these devices (physics-Hake 1998; science-Hatch, Jensen and Moore 2005; biology-Wood 2004; Carnevale 2005; medicine-Schackow 2004; Draper and Brown 2002; engineering-Industrial Engineer 2005; programming-Cutts and Kennedy 2005; veterinary medicine-Draper and Brown 2002; earth science-Greer and Heaney 2004). For example, Draper and Brown (2002) report on the use of PRDs at Glasgow University in a variety of fields (e.g., philosophy, psychology, medicine, and engineering). They note that students and faculty rate the experience as positive. In one class of 61 , no students found the PRDs "not at all useful," only $21 \%$ found the PRDs "not very useful" and all other responses were positive, with $18 \%$ finding the devices "extremely useful." PRDs seem to generally be accepted by students, perhaps in part due to the fact that they are not a new approach to teaching but rather an application of a new technology to existing instructional delivery methods (Simpson and Oliver 2005).

\section{BENEFITS OF PRDS}

Among the benefits of PRDs is that lectures can be altered "on-the-fly." In a traditional classroom, when an instructor asks a class if they understand a particular concept, most students will nod agreement even if they do not understand, not wanting to draw attention to themselves. By having students respond using PRDs, instructors receive immediate feedback on the percentage of students that understand and can apply a concept (Wood 2004). Instructors can then address topics that are misunderstood by large proportions of students. This differs from the traditional situation in which time might be spent on a given topic based on a lecturer's inaccurate perception of students' understanding (Draper and Brown 2002).

Not only does the PRD system provide immediate feedback to the instructor, it does so while still protecting the students' anonymity in the classroom setting (Duncan 2005). Skiba and Barton (2006) found that the Net Generation likes anonymity. Formal classroom activities are public, heightening students' concerns about their 
abilities (Meece, Blumenfeld and Hoyle 1988) and making students reluctant to speak up in class, an effect that is exaggerated in large classes. This is so even when class participation is an important component of the course grade. The use of PRDs allows students to participate mentally and to compare their understanding and knowledge with other students', while still maintaining their public anonymity. Students with PRDs may even feel empowered as they may be able to anonymously influence a lecture to focus on aspects of the material that they do not understand.

Along with giving immediate feedback, PRDs allow very rapid posting of grades. Chickering and Gamson (1987) enumerated 7 principles for good practice in undergraduate education; one of the principles is to give prompt feedback to students. Further, Murphy and Smark (2006) note that it is important that students receive feedback that is non-threatening and that allows them to take corrective action before exams and before they lose interest in the subject or drop the course. The Net Generation generally demands real-time, immediate processing, preferring, for example, instant messaging to e-mail (Skiba and Barton 2006). Prompt posting of results of students' responses to the grade book function of a CMS provides students with quick evidence of their advancement in the course and progress toward their grades.

There is currently some evidence that PRDs increase learning. Learning and memory research shows that through the process of elaborative rehearsal, active learning promotes long-term memory (McGlynn 2005). McGlynn (2005) also points out that the more connections there are to information, the more readily that information can be retrieved from memory. Use of PRDs on questions related to important points in the lecture may create additional connections to that information, leading to improved learning of the material. Studies also show that at a minimum, the use of PRDs increases students' attention (Herreid 2006; Jackson and Trees 2003), which increases long-term memory retention. Further, Cutts and Kennedy (2005) report that students that used PRDs generally performed better on examinations than students who did not use their PRDs.

Scholars also find that PRDs increase students' attendance in class (Duncan 2005). This is important since, as Marburger (2001) found, students do not test as well on material covered when they were absent from class as when they were present. So, when students have opportunities, such as those offered by PRD use, to earn credit during class (an extrinsic motivator) for attendance (or for correctly responding to interactive questions) it follows that students would be more likely to attend lectures and therefore perform better on examinations. Bacdayan (2004) finds that such extrinsic motivators may be increasingly important to students, and may, in part, explain the increased class attendance when PRDs are utilized regularly.

Simpson and Oliver (2005) and Draper and Brown (2002) report that PRDs can increase student motivation and achievement while also encouraging faculty to engage and interact with their students. PRD systems have the capability of making lectures more engaging and interesting to students (Draper and Brown 2002). PRDs have been shown to increase student interest in a class (Duncan 2005). Student interest is important because students who believe that a course is interesting are more likely to be intrinsically motivated and to engage in deep cognitive learning (for example elaboration or critical thinking) or metacognitive learning (thinking about how they learn) (Young 2005) than those who do not view the course in the same light.

Lincoln (2008) identifies 5 challenges faced by instructors of large classes. These are: getting students to attend, keeping students' attention when they do attend, getting students to participate actively in their learning, obtaining immediate feedback on student understanding so lectures can be altered in real time, and managing the workload of grading student work such as quizzes.

We find little reason to believe that use of clickers in business classes, in general, will result in significantly different findings than in other disciplines. Nevertheless, the technology should be put to the test. Next we develop propositions that can be tested in large sections of business courses. 


\section{PROPOSITION DEVELOPMENT}

Based on current literature regarding PRDs and NetGen students, we have developed propositions that should be tested with respect to acceptance, utilization, and utility of PRDs in teaching business courses. Today's students have been brought up using remote controls, Nintendos, i-Pods, computers and many other electronic devices. We believe that they will have no difficulty using PRDs, and hence:

Proposition 1: $\quad$ Students will have little difficulty adapting to the use of PRDs and will find the devices easy to use.

Because of the opportunity for greater involvement with course material provided through the use of interactive questions and PRDs and to the extent that PRDs encourage active learning, they are expected to increase deep learning by students. In addition, if credit toward the course grade is earned through using PRDs, student learning will improve because students attend lectures more frequently. Thus, we propose:

Proposition 2: $\quad$ Students will learn course material better when using PRDs than if PRDs are not used.

In large lecture sessions, most students are reluctant to speak up, whether to ask or answer questions. Large lectures are impersonal and students can easily remain anonymous to the teachers and to most of their peers. In this environment students often feel detached or remote because they have little or no interaction with their teachers. PRDs represent a way for students to interact and to test their understanding of course material when interactive questions are asked. Thus:

Proposition 3: $\quad$ Students feel more engaged in large lecture settings when PRDs are used.

Because of the change from being passive observers to active participants, we expect students that use PRDs will stay focused or be able to refocus on lectures.

Proposition 4: $\quad$ Students are more focused on lecture materials when PRDs are used throughout the lecture.

Because PRDs are interactive, requiring thought and action on the part of students, and because students receive instant feedback on their performance, we propose:

Proposition 5: $\quad$ Students view time in class devoted to the use of PRDs as time well spent.

Since students perform activities which will improve their grades, and since PRDs give both immediate and non-threatening feedback on students' responses to questions on interactive slides, we propose:

Proposition 6: $\quad$ Students place value on receiving the immediate feedback that is possible from their performance using PRDs.

Because students are eager to earn points toward their final course grades, when students can earn credit toward their course grades by using PRDs in class, we believe attendance will increase in large lecture classes, thus:

Proposition 7: $\quad$ Student attendance is higher when PRDs are utilized regularly in class as a means of earning credit toward the course grade.

We believe that students will evaluate the usefulness of PRDs in a manner similar to that used by consumers when making the consumer satisfaction judgment (consumers make judgments about their levels of overall satisfaction about goods or services by combining their satisfaction judgments of the individual components of satisfaction to reach an overall evaluation (Patterson, Johnson and Spreng 1997)). Thus:

Proposition 8: $\quad$ Students make their overall assessments of the usefulness of PRDs in class by combining their judgments of the individual characteristics of the PRDs. 
Discussion in large sections is typically difficult to start and sustain. Students seek anonymity and fear embarrassment in front of so many of their peers. Perhaps by polling the class on a discussion question (a question with no right or wrong answer) students will be more willing to speak out after seeing that many others in the class have the same viewpoint. Thus:

Proposition 9a: $\quad$ Use of clickers to respond to discussion questions leads to more students participating in inclass discussions.

Not only might more students be willing to speak out, but the diversity of viewpoints expressed might be greater when students see that there is disagreement among their peers. Thus:

Proposition 9b: $\quad$ Use of clickers to respond to discussion questions leads to expression of more points of view in in-class discussions.

Students often perceive little added value gained from reading the text. Interactive questions covering required readings for the day may act like pop-quizzes, encouraging students to read the text or other readings, prior to class. When students read the text prior to class, learning is enhanced. Thus:

Proposition 10a: $\quad$ More students read assigned readings prior to class when interactive questions about the readings are asked during each class period.

Proposition 10b: $\quad$ Student learning is enhanced when students read assigned readings prior to class.

Reviewing important concepts from the preceding class helps to reinforce learning. At the beginning of each class, interactive questions designed to encourage thinking about the material covered during the prior class period increase student rehearsal and learning. Thus:

Proposition 11: $\quad$ Student learning is enhanced when interactive questions about important concepts from the prior lecture are used at the beginning of each lecture.

Next we discuss some of the experience gained from conducting two studies in which PRDs were utilized in large sections of the Principles of Marketing course at a large Midwestern university.

\section{RESULTS OF ADOPTION OF PRDS}

PRDS were used during the Fall (Study I) and Spring (Study II) semesters in the Principles of Marketing course; the same instructor taught the course during both semesters. The course was required of all business majors, advertising majors, and business minors and was frequently taken by engineering students and others wishing to learn about marketing. All students enrolled in the classes had attained junior standing or higher. The Fall semester was the first time the instructor had used PRDs; similarly, for many of the students it was their first experience using PRDs.

For both studies each student purchased his or her own PRD and used the same PRD each class period. Presentation software and the PRD-system software were installed on the instructor's tablet computer, which was carried to each lecture hall and connected to a data projector. This arrangement allowed the instructor to save participant lists (files linking each student to his/her PRD) and session files (records of each individual PRD response in each class) from each section on the instructor's machine. By having the files stored on the instructor's computer, concerns about security of student grade information were minimized. This also meant that the software did not have to be installed on the computer system in each lecture hall, and that updates to the system were accomplished by updating only one computer. 


\section{Study I}

During each class session, students were asked to respond to each interactive slide. All responses to each question from participating students during a class period were saved in a "session file" and one session file was created for each class period; session files consisted of a row for each student's responses and a column for each interactive question. Students received credit for a class if they responded to every interactive question posed during that class; correct responses counted the same as incorrect responses; in effect, this gave students credit for attendance.

Each class was started on time with 3-6 interactive questions. By beginning each lecture with slides that counted toward the day's attendance credit, students were encouraged to be in their seats on time and ready for class to begin. The initial interactive slides reviewed material from the prior lecture and if a substantial number of students got an answer wrong it provided an opportunity to address the topic again. After the initial interactive slides, new interactive slides were used every 15-20 minutes to test students' understanding of the material from the current lecture and to reengage students with the material.

To collect data on student perceptions of PRDs, surveys were administered toward the end of the semester. The "embedded-URL" survey method was employed (Bradley 1999); e-mails containing hot links to online surveys were sent to students who volunteered to participate. These students then completed the surveys online. Because the surveys were conducted toward the end of the semester, students had ample opportunity to assess the value of the technology and its impact on their learning and study habits prior to the collection of data.

Student enrollment in the study and collection of data were handled by an independent third party so that students could participate without any fear of repercussions from their answers or from non-participation. No inducement was used to encourage student participation. Of the 644 students who completed the course, 193 completed the survey for a response rate of 30\%. All survey questions used 5-point scales with each end and the center anchored. Table 1 shows the weighted average result, with 1 corresponding to the lowest rating and 5 corresponding to the highest rating. Table 2 shows the percentages of respondents who chose the top two responses and those who chose the bottom two responses.

\section{Table 1: Student Perceptions Of PRDs}

\begin{tabular}{|c|c|c|}
\hline & $\underline{\text { Study I Mean }}$ & $\underline{\text { Study II Mean }}$ \\
\hline PRDs are easy to use & 3.46 & 3.96 \\
\hline PRDs help students learn course material & & 3.31 \\
\hline Students are more likely to attend lecture because of PRDs & 4.35 & 4.45 \\
\hline PRDs increase students' sense of engagement in lecture & & 3.89 \\
\hline PRDs make class more enjoyable & & 2.92 \\
\hline PRDs help students remain focused on lecture & & 3.67 \\
\hline $\begin{array}{l}\text { PRDs reviewing material from prior class represents good use of class } \\
\text { time }\end{array}$ & & 4.01 \\
\hline Students like immediate in-class feedback from interactive slides & 3.65 & \\
\hline Students like having grades posted quickly to an online grade book & & 4.22 \\
\hline Overall PRDs are useful & 2.79 & 3.26 \\
\hline
\end{tabular}


Table 2: Percentages Of Students' Ratings With Scale Extremes

\begin{tabular}{|c|c|c|c|c|}
\hline \multicolumn{5}{|c|}{$\begin{array}{l}\text { Percentages represent the proportions of respondents who selected one of the two highest or two lowest ratings for the respective } \\
\text { measures. Empty cells indicate that item was not surveyed during the corresponding semester. All items used a 5-point scale. }\end{array}$} \\
\hline & \multicolumn{2}{|c|}{ Study I } & \multicolumn{2}{|c|}{ Study II } \\
\hline & High Rating & Low Rating & High Rating & Low Rating \\
\hline PRDs are easy to use & 50.8 & 19.7 & 71.1 & 6.9 \\
\hline PRDs help students learn course material & & & 53.4 & 24.0 \\
\hline $\begin{array}{l}\text { Students are more likely to attend lecture because } \\
\text { of PRDs }\end{array}$ & & & 87.2 & 3.9 \\
\hline $\begin{array}{l}\text { PRDs increase students' sense of engagement in } \\
\text { lecture }\end{array}$ & & & 73.6 & 3.0 \\
\hline PRDs make class more enjoyable & & & 36.8 & 37.2 \\
\hline PRDs help students remain focused on lecture & & & 69.6 & 16.2 \\
\hline $\begin{array}{l}\text { PRDs reviewing material from prior class } \\
\text { represents good use of class time }\end{array}$ & & & 74.1 & 10.8 \\
\hline $\begin{array}{l}\text { Students like immediate in-class feedback from } \\
\text { interactive slides }\end{array}$ & 55.5 & 12.4 & & \\
\hline $\begin{array}{l}\text { Students like having grades posted quickly to an } \\
\text { online grade book }\end{array}$ & & & 80.4 & 8.8 \\
\hline Overall PRDs are useful & 32.6 & 43.0 & 44.1 & 25.5 \\
\hline
\end{tabular}

\section{Study II}

Study II was conducted during the Spring semester. In Study II, instead of attendance, students earned credit for correct answers to interactive questions. In addition to the types of interactive questions posed during Study I, some interactive slides asked opinions for which there were no right or wrong answers, but the activity nevertheless served to reengage students; for these questions, credit was given for any response. As in the prior study, each lecture began with 3-6 interactive slides covering topics from the prior lecture. During both studies it was noted that very few students came late to class; this was true even during Study II when classes began at 8:30 a.m. Similarly, few students left class early. Likely this was because the students were able to earn credit toward their course grades by responding to the interactive questions.

Of the 669 students completing the course (one large section), 204 students completed the survey for a response rate of $30.5 \%$. Results of the survey are summarized in Tables 1 and 2. No attempt was made to check for selection bias in either Study I or Study II.

\section{DISCUSSION}

Results of the surveys conducted during Studies I and II are summarized in Table 1. Blank cells indicate that the survey items were not asked during the respective semesters.

Some technical difficulties were experienced during Study I. For example, there were some problems linking students' names and their id numbers with the id numbers of their respective PRDs. In addition some technical issues that were sorted out by mid-semester negatively affected students' perceptions of the ease of use of the devices. Nevertheless, student acceptance and tolerance seemed quite high. In both semesters students found the devices easy to use, though the second semester mean "ease of use ratings" increased from 3.46 to 3.96 and the percentage of students rating the devices as either "excellent" or "very good" on ease of use increased from 50.8\% in the Fall to $71.1 \%$ in the Spring. This increase is likely because fewer technical difficulties were encountered during the Spring semester.

More significant than being easy to use, PRDs did appear to increase student learning with $53.4 \%$ of respondents agreeing or strongly agreeing that the devices helped them learn course material during the Spring semester. Only $7.8 \%$ of the students strongly disagreed that the PRDs aided in learning course material. This finding is important because it shows that in large sections of classes, use of PRDs has a positive influence on the students' perception of learning. 
The manner in which PRD usage is graded influences student reactions to the use of PRDs. For example, during the fall semester students were given credit for attending a lecture only if they responded to every interactive slide during that particular lecture. On course evaluations, students expressed frustration that this practice 'treated them like children,' checking up on their attendance. In particular, students were not penalized for responding incorrectly and expressed that they would have preferred to have had the interactive questions graded so that they would be rewarded for correct answers. Interestingly, although there was no direct incentive during the fall semester for students to answer correctly, it appeared that most students tried to do so. We speculate that this was due to a desire to "be right" and also to find out whether they really did understand the topic.

In the spring semester students were given credit only for correct responses; correct responses earned points toward their final course grades. In each semester credit for using PRDs represented about $10 \%$ of the course grade (9.7\% in the fall and $11.8 \%$ in the spring). In the spring, when correct responses earned credit, there was less resentment expressed by students when they completed the course evaluation survey.

For the fall semester, 92\% of students earned full credit for PRD usage. For the spring semester when students earned credit for correct answers, $88 \%$ of the students earned the maximum possible points for clicker usage. In contrast, Cutts and Kennedy (2005) loaned PRDs to students but did not require that students either bring the PRDs to classes or that the students use the PRDs in classes. Non-response rates (students who had their clickers with them but did not respond to the interactive questions) were typically around $20 \%$ with another $15 \%$ of students having forgotten to bring their devices. This leads us to conclude that giving some sort of extrinsic reward for PRD usage (credit for attendance, extra-credit, or credit for correct answers) is important in order to engage students more fully in lectures.

Students reported that they felt more engaged with the course material when using PRDs than they would have had the devices not been used. They also reported they were more focused on the lecture when using PRDs. Because students were more engaged, we infer that PRDs help more students engage in deep cognitive or metacognitive learning (Young 2005), and hence would be expected to perform better on exams and retain their learning longer than students who do not use PRDs. Student views are consistent with this, with a majority of students rating the PRDs as valuable in their learning experience. While the class averages on exams were very close during both semesters, the exams differed between the two semesters so exam grades are not a good measure of learning.

On the spring semester survey, students were asked "Overall, has the clicker made the whole course more enjoyable or less enjoyable?" The mean of 2.92 indicates that students did not find the class more enjoyable than other courses that do not use clickers.

During the fall semester when, PRDs were essentially used to measure attendance, students reported that overall the devices were not useful $(\mu=2.79)$. This changed during the spring when students were given credit for correct answers to questions; students reported that overall, PRDs are useful $(\mu=3.26)$.

In summary, the most significant impact of PRDs appears to be on student learning, followed closely by class attendance, students' perceptions of participation, and staying focused on lectures and engaged with course material. The next section deals with recommendations or best practices for instructors adopting PRDs for use in their classes.

\section{OBSERVATIONS AND RECOMMENDATIONS FOR INSTRUCTORS}

Because PRDs are a relatively new technology, in general, and appear to be very new in business courses, we offer a few observations and recommendations for instructors adopting PRDs for the first time.

Simply adopting PRDs because they are a new technology or to demonstrate that the instructor is open to new approaches "will not bring you enthusiastic, actively engaged learners" (Murphy and Smark 2006, p. 188). Instructors need to be familiar with the hardware and software (training and assistance is often available from the vendors) and should work the interactive components into their presentations in ways that follow and add to the structure of their lectures. 
While PRDs give instructors the ability to take attendance easily, students reacted quite negatively to the perception that the primary use of the PRDs was to monitor or control their behavior. Instead, we recommend that faculty stress the use of PRDs as learning tools and as a means of increasing student engagement during lectures.

Since the current generation of students appears to demonstrate an increasing need for extrinsic motivators (Bacdayan 2004), and because quizzes and their impact on grades are a form of extrinsic motivation, PRDs can be expected to motivate students to learn course material when utilized regularly for grading purposes. This should be particularly true when used as a form of announced quiz, as announced quizzes have a stronger motivational impact than unannounced quizzes (Bacayan 2004).

When credit is given for PRD responses (whether for attendance or for correct answers) there may be a temptation for students to cheat. This temptation could be especially great in large sections in which instructors do not know all students by name or might even have difficulty counting the number of students present, making the likelihood of identifying breaches of academic integrity low. Two types of cheating are possible. One is for students to "peek" at their notes or talk with their neighbors when responding to interactive questions and the other is for "unauthorized" students to use other students' clickers. In the case of peeking or talking with neighbors, it was felt that this would be impossible to control with any degree of credibility or consistency in large lectures, so these actions were not considered cheating and students were encouraged to take these actions. An additional reason for this policy is that talking with neighbors had the potential to result in peer-to-peer learning, a powerful learning technique, while reviewing notes allowed students some activity and the opportunity to learn or re-learn material by reviewing it.

Unauthorized use of clickers was strongly discouraged. This could occur, for example, if one student said to a classmate, "you take my clicker to class and respond for me today and I'll take yours to class tomorrow." (During the course of this study students were caught cheating in this manner.)

The course syllabus should clearly address the issue of cheating and its consequences. The syllabi during both semesters reported in this study read as follows: "Each student must use his or her clicker only. Responding to a question using another student's clicker (whether that student is present or not) constitutes cheating on your part AND on the part of the other student" [emphasis in original]. Further, TAs roamed the aisles when interactive slides were shown both to assist students having difficulties with their PRDs and to watch for students using multiple PRDs.

The time allowed for students to respond to interactive questions can be varied for each interactive slide. Times on the order of 20-25 seconds seem reasonable for most students to respond to many questions that test knowledge or understanding. For longer and more difficult questions students may request additional time and many systems allow instructors to add additional time for responses if polling has not closed. With foreign students making up a significant proportion of U.S. university enrollments (U.S. Dept. of Education 2003), such a short time may prove difficult for some.

As noted previously, prompt feedback is considered good practice in undergraduate education and students reported that getting their grades promptly was important to them (Chickering and Gamson 1987). Therefore, we recommend that instructors giving credit for PRD responses post grades to an online grade book the same day as the class. We used the grade book function in a course management system for this purpose. Also, students should be told that they are responsible for checking the accuracy of those reported grades and that any errors not reported within a short time (e.g., 24 or 48 hours of the time that the grades are posted) will not be altered. This practice helps identify system problems or individual PRD problems promptly and is also a defense against students not attending lectures and then claiming their PRDs did not work during the entire semester.

Another recommendation concerns presenting enough interactive questions during the semester that students can miss a few classes and still earn the maximum amount of credit. For example, during the Spring semester a total of 120 interactive questions were presented for possible credit during lectures but students could earn the maximum amount of credit for this component of their course grades by correctly answering any 80 of those questions. If such a practice is used, it should be clearly explained to students and stated in the syllabus. For 
example, the course syllabus for the class described here stated that students would have a reasonable number of opportunities to earn full credit, even if they did not answer some questions due to forgetting their PRDs, to their PRDs not working, or to missing classes due to "illnesses, bad hair days, being abducted by aliens, hangovers, their roommate forgetting to wake them, the alarm not going off, or any other reasons." The number of questions students could miss and still receive full credit was clearly stated. Nevertheless, some students did not grasp the significance of the "excess" number of interactive questions. As a consequence, they requested credit for absences. These requests decreased as students understood that there was a sufficient number of "extra" questions to accommodate their situations.

One method to help students understand more quickly the benefits of the "extra" questions might be to divide the semester into natural parts, for example, using midterm exams as the dividing points. Instead of allowing, hypothetically, credit for a maximum of 80 interactive questions to be earned anytime during the semester, the instructor might allow credit to be earned for a maximum of 20 interactive questions prior to the first midterm exam, 30 after the first midterm and before the second midterm exam, and 30 after the second midterm and prior to the final exam. (Fewer interactive questions in the first third of the semester would allow time for registration of PRDs and for students to become familiar with PRD operation.) Spreading out the opportunities for students to earn credit for interactive questions might help students more quickly understand the implications of having "excess" interactive questions, resulting in higher student satisfaction with the grading scheme. This might also prevent another phenomenon that was observed: as more and more students earned the maximum credit available for correct responses to the interactive questions, attendance at lectures dropped noticeably. While attendance might drop toward the end of each part of the semester as students earn the maximum number of possible points, such a drop in attendance would be spread out over the semester more evenly than if the entire semester were graded as a whole.

Studies confirm that many students do not read assigned materials (Smart, Kelly and Conant 1999), a phenomenon we have also observed. This is unfortunate because it greatly decreases the quality of in-class discussions and makes lecture material seem less relevant to students. Consequently we began including some clicker questions at the beginning of the class period that were drawn directly from the readings. Anecdotal evidence indicated that the percentage of students who looked at the readings before class increased. While the same result might have been obtained by using pop-quizzes, interactive slides take much less class time to complete and allow both immediate correction of misunderstandings on the part of students and give the instructor an understanding of what topics need the most focus during the lecture.

Adoption by business educators of new and useful technologies as they become available could improve student learning and increase student enjoyment of the subject. PRDs appear to be one such technology, having already been adopted by educators in the sciences. Those business faculty that fear "being replaced by long-distance learning - the 'virtual university' concept" (Smart, Kelley, and Conant 1999) hasten that day by not adopting technologies that enhance learning in traditional classrooms and lecture halls and that make content more engaging to Net Gen, tech savvy, students. The rudiments of using PRDs can be learned with a little time and practice, and appear to enhance both student learning and student perceptions of learning.

\section{LIMITATIONS AND FUTURE RESEARCH}

This study was carried out in a large, Midwestern university. The results can likely to be generalized to other universities, but these results should be tested in other settings. The research should be replicated in other courses, such as supply chain management and marketing research, it should be tested in graduate-level courses, as well.

While some current research shows that active learning results in greater learning than passive learning (e.g., Tomkovick 2004; Hake 1998), one controlled experiment found that active learning does not increase learning significantly more than passive learning (Drafke, Schoenbachler and Gordon 1996). However, the same experiment found that students perceive that greater learning occurs when active learning techniques are used (Drafke, Schoenbachler and Gordon 1996). Since students' perceptions of learning rather, than learning itself, were surveyed in the case studies reported in this paper, it would be useful to design and conduct controlled experiments to determine whether PRDs increase actual learning. Further, at least one study has found that that no relationship 
exists between student self-reported learning and instructor assigned grades (Young, Klemz, and Murphy 2003). In spite of these findings, if students perceive that they are learning more through the use of PRDs, the devices may be beneficial in improving students' attitudes toward courses and course materials.

It is possible that students view the use of PRDs as a competitive exercise, pitting themselves against everyone else in the class. Young (2005) states that active learning exercises (such as the use of PRDs) that stress competitive performance can lead to increased extrinsic motivation of students. To the extent that this is so, PRDs may actually be detrimental to deep cognitive learning. Alternatively, the use of PRDs may increase feelings of autonomy, perceived competence, or task mastery, feelings that lead to increased intrinsic learning (Young 2005). We encourage research into this important aspect of PRD usage and development of strategies for PRD usage that promote intrinsic learning.

While acceptance of PRDs by students was generally quite positive, it would be interesting to know whether student acceptance changes as students become more accustomed to using PRDs in their classes.

\section{BEST PRACTICES}

During the first semester of use, one student approached the instructor after one of the initial classes in which PRDs were used and commented that he was glad the instructor was familiar with the operation of PRDs and the PRD software. The student had been in another course in which the instructor was not familiar with the software and used the classroom to learn how to operate the software. Thus, we encourage instructors interested in adopting the PRD technology to become thoroughly familiar with its operation prior to use in the classroom.

\section{CONCLUSION}

It appears that PRDs have many beneficial effects on student learning in large sections of introductory business courses, and could have other applications, as well. Among the benefits experienced are increased student perceptions of learning, increased student engagement with the material, improved student focus during lectures, and higher attendance in lectures.

How much students like a particular instructional method appears to be partially a matter of whether they have had previous classes in which the instructor used that method (Watters 2000). As PRDs gain acceptance in the classroom and are used more commonly in business classes, educators may find that students embrace the technology and come to expect its use. We encourage business educators to continue to research the use of PRDs and to adopt PRDs, where appropriate.

\section{ADKNOWLEDGEMENTS}

The authors thank Thomson Learning, Inc., Turning Technologies, Inc., the Reed Group, and the Office for Information Management at UIUC for their generous support of this research.

\section{AUTHOR INFORMATION}

Michael W. Preis, (Ph.D., The George Washington University, is a Clinical Professor of Business Administration at University of Illinois at Urbana-Champaign. His research interests include pedagogy, customer satisfaction, and selling and sales management.

Gregory M. Kellar, Ph.D., University of Tennessee, Knoxville, is an Assistant Professor of Supply Chain Management at Wright State University. He has published on various supply chain and pedagogy issues and his research interests include supply chain management and pedagogy.

Elizabeth Crosby, ABD, University of Illinois at Urbana-Champaign, is a PhD student in Business Administration at University of Illinois at Urbana-Champaign. She has published on consumer negotiations and her research interests include culture theory in consumer behavior and public policy. 


\section{REFERENCES}

1. Bacdayan, P. (2004). Comparison of management faculty perspectives on quizzing and its alternatives. Journal of Education for Business, 80, (1), 5 - 9.

2. Barr, R. B. \& J. Tagg (1995). From teaching to learning-A new paradigm for undergraduate education. Change, 27, (6), $12-25$.

3. Bradley, N. (1999). Sampling for Internet surveys, An examination of respondent selection for Internet research. Journal of the Market Research Society, 41, (4), 387 - 395.

4. Burnstein, R. A. \& L. M. Lederman (2006). The use and evolution of an audience response system, in Audience response systems in higher education: Applications and cases, David A. Banks, ed., Hershey, Information Science.

5. $\quad$ Carbone, E. (1998). Teaching Large Classes: Tools and Strategies, Thousand Oaks, Sage.

6. Carnevale, D. (2005). Run a class like a game show: 'Clickers' keep students involved. Chronicle of Higher Education, 51, (42), B3.

7. Chickering, A. W. \& Z. F. Gamson (1987). Seven principles for good practice in undergraduate education. AAHE Bulletin. 39, (7), 3 - 7. Cited in Arthur W. Chickering \& Zelda F. Gamson (1999). Development and adaptations of the seven principles for good practice in undergraduate education. New Directions for Teaching \& Learning, 80, $75-81$.

8. Clarke, I., T. B. Flaherty \& S. Mottner (2001). Student perceptions of educational technology tools. Journal of Marketing Education, 23, (3), 169 - 177.

9. Coker, D. R. \& J. White (1993). Selecting and applying learning theory to classroom teaching strategies. Education, 114, (1), $77-80$.

10. Cutts, Q. I. \& G. E. Kennedy (2005). Connecting learning environments using electronic voting systems. Retrieved June 26, 2006 from: http://www.dcs.gla.ac.uk/ quintin/papersCRPITV42Cutts.pdf

11. Davis, R., S. Misra \& S. Van Auken (2002). A gap analysis approach to marketing curriculum assessment: A study of skills and knowledge. Journal of Marketing Education, 24, (3), 218 - 224.

12. Drafke, M. W., D. D. Schoenbachler \& G. L. Gordon (1996). Active and passive teaching methodologies: student outcomes over a semester course. Marketing Education Review, 6, (1), 9 - 17.

13. Draper, S. W. and M. I. Brown (2002). Use of PRS (Personal Response System) handsets at Glasgow University. Retrieved July 2, 2006 from: http://www.psy.gla.ac.uk/ steve/ilig/interim.html

14. Drea, J. T., C. Tripp \& J. K. Stuenkel (2005). An assessment of the effectiveness of an in-class game on marketing students' perceptions and learning outcomes. Marketing Education Review, 15, (1), 25 - 33.

15. Eastman, J. K. \& C. O. Swift (2001). New horizons in distance education: The online learner-centered marketing class. Journal of Marketing Education, 23, (1), 25 - 34.

16. Ferrell, L. \& G. Gonzalez (2004). Beliefs and expectations of principles of marketing students. Journal of Marketing Education, 26, (2), 116 - 122.

17. Goldfinch, J. (1996). The effectiveness of school-type classes compared to the traditional lecture/tutorial method for teaching quantitative methods to business students. Studies in Higher Education, 21, (2), 207 220.

18. Granitz, N. \& P. Hugstad (2004). Creating and diffusing a technology champion course. Journal of Marketing Education, 26, (3), 208 - 225.

19. Greer, L. \& P. J. Heaney (2004). Real-time analysis of student comprehension: An assessment of electronic student response technology in an introductory earth science course. Journal of Geoscience Education, 52, (4), 345 - 351.

20. Hake, R. R. (1998). Interactive-engagement versus traditional methods: A six-thousand-student survey of mechanics test data for introductory physics courses. American Journal of Physics, 66, (1), $64-74$.

21. Hatch, J., M. Jensen \& R. Moore (2005). Manna from heaven or clickers from hell: Experiences with an electronic response system. Journal of College Science Teaching, 34, (7), 36 - 39.

22. Horowitz, H. M. (2006). ARS evolution: Reflections and recommendations, in Audience response systems in higher education: Applications and cases, David A. Banks, ed., Hershey, Information Science.

23. Industrial Engineer (2005). Clicking for scholars. Industrial Engineer, 37, (7), 66.

24. Lincoln, D. J. (2008). Teaching with clickers in the large-size principles of marketing class. Marketing Education Review, 18, (1), 39 - 45. 
25. Marburger, D. R. (2001). Absenteeism and undergraduate exam performance. Journal of Economic Education, 32, (2), 99 - 109.

26. McGlynn, A. P. (2005). Teaching millenials, our newest cultural cohort. Education Digest, 71, (4), 12 16.

27. Meece, J., P. Blumenfeld \& R. Hoyle (1988). Students' goal orientations and cognitive engagement in classroom activities. Journal of Educational Psychology, 80, (4), 514 - 523.

28. Murphy, B. \& C. Smark (2006). Convergence of learning experiences for first year tertiary commerce students-Are personal response systems the meeting point? Journal of American Academy of Business, 10, (1), $186-191$.

29. Patterson, P. G., L. W. Johnson \& R. A. Spreng (1997). Modeling the determinants of customer satisfaction for business-to-business professional services. Journal of the Academy of Marketing Science, 25, (1), 4 - 17.

30. Peterson, R. M. (2002). Course participation: An active learning approach employing student documentation. Journal of Marketing Education, 23, (3), 187 - 194.

31. Schackow, T. E., M. Chavez, L. Loya \& M. Friedman (2004). Audience response system: Effect on learning in family medicine residents. Family Medicine, 36, (7), 496 - 504.

32. Simpson, V. and M. Oliver (2006). Using electronic voting systems in lectures. Retrieved June 21, 2006 from: http://www.ucl.ac.uk/learningtechnology/examples/ElectronicVotingSystems.pdf

33. Skiba, D. \& A. Barton (2006). Adapting your teaching to accommodate the next generation of learners. Journal of Issues in Nursing, 11, (2), 15.

34. Smart, D. T., C. A. Kelley and J. S. Conant (1999). Marketing education in the year 2000: Changes observed and challenges anticipated. Journal of Marketing Education, 21, (3) 206 - 216.

35. Stern, B. L. and L. P. D. Tseng (2002). Do academics and practitioners agree on how to teach the undergraduate marketing research course? Journal of Marketing Education, 24, (3), 225 - 232.

36. Tomkovick, C. (2004). Ten anchor points for teaching principles of marketing," Journal of Marketing Education, 26, (2), $109-115$.

37. U.S. Department of Education (2003). Digest of education statistics tables and figures 2003. Retrieved July 21, 2006 from: http://nces.ed.gov/programs/digest/d03/tables/dt417.asp

38. Wallis, C., W. Cole, S. Steptoe \& S. S. Dale (2006). The multitasking generation. Time, 167, (13), $48-55$.

39. Watters, M. (2000). Reciprocal questioning and computer-based instruction in introductory auditing: Student perceptions. Journal for Education in Business, 75, (5), 263 - 66.

40. Wood, W. B. (2004). A teaching gimmick that works. Developmental Cell, 7, (6), 796 - 98.

41. Young, M. (2001). Windowed, wired, and webbed-Now what? Journal of Marketing Education, 23, (1), $45-54$.

42. Young, M. (2005). The motivational effects of the classroom environment in facilitating self-regulated learning. Journal of Marketing Education, 27, (1), 25 - 40.

43. Young, M., B. R. Klemz \& J. W. Murphy (2003). Enhancing learning outcomes: Effects of instructional technology, learning styles, instructional methods, and student behavior. Journal of Marketing Education, $25,(2), 130-142$. 